\title{
A proposed framework to improve the safety of medical devices in a Canadian hospital context
}

This article was published in the following Dove Press journal:

Medical Devices: Evidence and Research

16 May 2014

Number of times this article has been viewed

\author{
Julie Polisena ${ }^{1,2}$ \\ Jeffrey Jutai ${ }^{3}$ \\ Rana Chreyh ${ }^{4}$ \\ 'Canadian Agency for Drugs and \\ Technologies in Health, Ottawa, ON, \\ Canada; ${ }^{2}$ Department of Epidemiology \\ and Community Medicine, \\ Faculty of Medicine, University \\ of Ottawa, Ottawa, ON, Canada; \\ ${ }^{3}$ Interdisciplinary School of Health \\ Sciences, Faculty of Health Sciences, \\ University of Ottawa, Ottawa, ON, \\ Canada; ${ }^{4}$ Biomedical Engineering, \\ The Ottawa Hospital, Ottawa, ON, \\ Canada
}

Purpose: Medical devices are used to monitor, replace, or modify anatomy or physiological processes. They are important health care innovations that enable effective treatment using less invasive techniques, and they improve health care delivery and patient outcomes. Devices can also introduce risk of harm to patients. Our objective was to propose a surveillance system framework to improve the safety associated with the use of medical devices in a hospital.

Materials and methods: The proposed medical device surveillance system incorporates multiple components to accurately document and assess the appropriate actions to reduce the risk of incidents, adverse events, and patient harm. The assumptions on which the framework is based are highlighted. The surveillance system was designed from the perspective of a tertiary teaching hospital that includes dedicated hospital staff whose mandate is to provide safe patient care to inpatients and outpatients and biomedical engineering services.

Results: The main components of the surveillance system would include an adverse medical device events database, a medical device/equipment library, education and training, and an open communication and feedback strategy. Close linkages among these components and with external medical device/equipment networks to the hospital must be established and maintained. A feedback mechanism on medical device-related incidents, as well as implementation and evaluation strategies for the surveillance system are described to ensure a seamless transition and a high satisfactory level among the hospital staff. The direct cost items of the proposed surveillance system for consideration, and its potential benefits are outlined.

Conclusion: The effectiveness of the proposed medical device surveillance system framework can be measured after it has been implemented in a Canadian hospital facility.

Keywords: surveillance system, safety, training, adverse events, devise failure, maintenance

\section{Background}

A medical device is used to diagnose, treat, or prevent a disease or abnormal physical condition without any chemical action in the body, as defined by the US Food and Drug Administration (FDA). ${ }^{1}$ Between 2004 and 2009, sales of medical devices increased by $56 \%$, while pharmaceutical sales rose by $38 \%$ during the same period. ${ }^{2}$ The medical device industry, which includes product areas such as cardiovascular and orthopedic devices, wound care products, disposable supplies, and durable equipment, is a US\$200 billion business worldwide, with projected sales of US\$95 billion in 2010 in the US alone. ${ }^{2}$ Medical devices are important health care innovations, enabling effective treatment using less invasive techniques, and improving health care delivery and patient outcomes, but they can also be harmful to patients. An audit conducted by the UK National Patient Safety Agency reported that device-related incidents are caused by device failure $(43.8 \%)$, inappropriate use $(29.3 \%)$, lack of training $(12.3 \%)$, and poor maintenance $(1.5 \%){ }^{3}$
Correspondence: Julie Polisena CADTH 600-865 Carling Ave, Ottawa ON KIS 5 S8 Canada

$\mathrm{Tel}+\mathrm{I} 6132262553$

$\mathrm{Fax}+\mathrm{I} 6132265392$

Email juliep@cadth.ca submit your manuscript | www.dovepress.com

Dovepress

http://dx.doi.org//0.2147/MDER.S61728
Medical Devices: Evidence and Research 2014:7 139-147 139 (c) (i) (5) 2014 Polisena et al. This work is published by Dove Medical Press Limited, and licensed under Creative Commons Attribution - Non Commercial (unported, v3.0) License. The full terms of the License are available at http://creativecommons.org/licenses/by-nc/3.0/. Non-commercial uses of the work are permitted without any further permission from Dove Medical Press Limited, provided the work is properly attributed. Permissions beyond the scope of the License are administered by Dove Medical Press Limited. Information on
how to request permission may be found at: http://www.dovepress.com/permissions.php 
In the US, domestic and foreign manufacturers are required by the Good Manufacturing Practices regulations to have a quality system for the design and production of medical devices that are intended to be sold in the country. ${ }^{4}$ The primary objective of the quality system is to prevent defects in the design, manufacture, and shipment of products. The Quality System Regulation requirements for device manufacturers are as follows: various specifications and controls for the devices must be in place for devices; devices must be designed under a quality system; finished devices must meet these specifications; devices must be correctly installed, checked, and serviced; quality data must be analyzed to identify and correct quality problems; and complaints must be processed. Customer feedback on a regular basis, system audits, management reviews, and corrective and preventive actions are required for the system to remain dynamic and ensure improvements in the medical device, labeling, packaging, or quality system. ${ }^{4}$ In Canada, the medical device industry must have a quality system certificate issued by the Canadian Medical Devices Conformity Assessment System as proof that manufacturers have complied with the appropriate regulatory system requirement. Class I medical devices and importers or distributors of medical devices do not have any regulatory quality system requirement. ${ }^{5}$

Post-market surveillance (PMS) represents a feasible means of reducing the risk of adverse medical device events (AMDEs) that are detectable and traceable. This approach would prospectively monitor safety and effectiveness; more rapidly identify and communicate incident data to avoid further events; guide the development of training, organizational process improvement, or other patient safety interventions; and direct decision making about funding or replacement by purchasers and policymakers. Medical device problems may surface years after they have been used or implanted in thousands of patients. As major changes to the medical device approval process are unlikely in the near future, policies intended to detect and reduce harms of medical devices must instead target the PMS space. The FDA published two reports in 2012 and 2013 on strengthening their national system for medical device PMS. ${ }^{6}$ The national surveillance system is intended to effectively communicate accurate information on the benefits, risks, and safety signals associated with the use of medical devices, from reliable data sources in a cost-effective manner, and simplify regulatory approval for new and current devices. The actions outlined to help achieve the desired functionality of the surveillance system are the 1) introduction of a unique device identification system; 2) establishment of national and international device registries; 3) update of existing adverse event reporting and analysis; and 4) development and use of new research methodologies for evidence generation, synthesis, and appraisal. ${ }^{7}$

Health Canada is responsible for the surveillance and reporting of device advisories, warnings, or recalls and posts this information in the Advisories, Warnings and Recall Database and Drug and Medical Device Recall Listing available on their website. ${ }^{8}$ The regulator issues device advisories, warnings or recalls by rich site summary (RSS), Twitter, email, and web postings, but if clinicians are not aware of or communicating this information to patients, patients are not providing fully informed consent about potential risks to which they may be exposed. An Auditor General review, however, has recommended improved collection and analysis of PMS data and communication of safety concerns to all stakeholders. ${ }^{9}$ Ideally, information about device safety, clinical effectiveness, and potential risks communicated to clinicians would then be shared with patients for shared decision making about device use. This is fundamental to ethical and patient-centered care. ${ }^{10-12}$

Although a medical device surveillance system is deemed to be an effective approach to the improvement of medical device safety in a hospital, the adoption and appropriate use of such a system has been slow in practice. ${ }^{13}$ Challenges associated with PMS include the identification of data sources with relevant medical device data and the exposure of a patient population to a specific medical device. ${ }^{14}$ It is possible that device-related adverse events are underreported, since manufacturers usually are not obliged to actively search for device malfunctions. ${ }^{15}$ Furthermore, there may be a disincentive to report adverse events or device malfunctions if health care providers use them for indications or patient populations not originally approved by the regulatory authority (ie, off-label use). ${ }^{15,16}$

A systematic review on factors that influence the recognition, reporting, and resolution of medical-device related incidents in hospitals has identified five themes related to barriers to medical error reporting by health care professionals. They involve reporter burden, professional identity (eg, fear of being perceived as incompetent), information gap (eg, lack of awareness of existing surveillance system or inability to recognize incident), organizational factors (eg, perception that current surveillance system is ineffective in reducing risk of medical device-related incidents), and fear (Polisena et al, unpublished data, 2014). These barriers can also be extrapolated to medical device error reporting. Results of included studies in the systematic review also suggest that fear of legal ramifications, workplace discrimination, and uncertainty on 
what to report and how the reports will help to improve the health care system may also prevent the reporting of medical errors (Polisena et al, unpublished data, 2014).

Reduction in barriers for better dissemination of adverse event analysis is needed, as is an understanding of the litigation impact of all stakeholders. ${ }^{17}$ Non-punitive and confidential volunteer reporting programs would provide health care professionals with the opportunity to tell the complete story without the fear of retribution. According to Cohen, ${ }^{18}$ practitioners who are forced to report errors are less likely to provide in-depth information because their primary motivation is self-protection and adherence to a requirement, not to help others avoid the same tragedy. In addition to AMDEs and device malfunctions, voluntary programs can encourage practitioners to report hazardous situations and errors that did not cause harm but have the potential to do so. An important factor in the quest for improving the safety of medical devices is broader immunity for error reports and a non-punitive culture that places a higher value on resolving system-based problems than on punishing practitioners for errors. ${ }^{18,19}$

Numerous incentives can be used to improve the safety of medical devices. Some effective incentives identified in the literature and telephone interviews with frontline clinicians to increase medical error reporting include no culture of blame associated with the person who reported the error, as well as patient and provider protection, and professional compliance (Polisena et al, unpublished data, 2014). ${ }^{20}$ These incentives for incident reporting would encompass protection from legal action and fear of criticism, blame, or disapproval. A medical device surveillance system could improve patient care and overall patient safety throughout the duration of a hospital stay. Errors with greater perceived severity will be likely to be reported by health care professionals (Polisena et al, unpublished data, 2014). ${ }^{20}$ One important success factor that will enhance the safety of medical devices is to gain trust from the frontline health care providers and ensure that their incident reports will be reviewed to resolve the errors and prevent future similar errors. These individuals, therefore, should be kept abreast of any relevant developments and receive timely feedback. ${ }^{21}$

\section{Proposed framework to improve the safety of medical devices in a Canadian hospital context}

AMDEs have been found to occur 83.7 times per 1,000 hospital admissions. ${ }^{22}$ Despite this phenomenon, there is a dearth of evidence on the evaluation of post-market medical device surveillance in a hospital setting (Polisena et al, unpublished data, 2014). Although there are medical device regulations in Canada, we were unable to identify any literature on frameworks for medical device surveillance in hospital facilities. We therefore propose a framework to improve the safety associated with the use of medical devices on patients in a Canadian hospital context. Polisena et al's systematic review (Polisena et al, unpublished data, 2014) on factors that influence the recognition, reporting, and resolution of incidents related to medical devices and other health care technologies and a qualitative study (Polisena et al, unpublished data, 2014) on frontline clinicians' experiences with medical devices has helped to inform the development of the proposed framework. For the qualitative study, telephone interviews were conducted among 12 surgeons and four registered nurses in two tertiary care hospitals in Ontario, Canada. Respondents were asked to discuss factors that influence the recognition, reporting, and resolution of medical device-related incidents according to their professional experience, as well as interventions or strategies to improve medical device hospital surveillance (Polisena et al, unpublished data, 2014).

\section{Assumptions}

The proposed medical device surveillance system framework was developed under the following assumptions:

- The framework for the medical device surveillance system was drafted from a tertiary academic hospital perspective in a Canadian setting. The hospital had an established Center for Patient Safety with a mandate to provide safe patient care to both inpatients and outpatients through continuous research, education, and evaluation methods.

- The Center employed three to four staff members.

- The hospital provided biomedical engineering services, whose primary responsibility was to test and implement new devices, maintain medical equipment, and act as advisors to the selection of medical equipment.

- A medical device surveillance system currently did not exist at the hospital.

Figure 1 presents the proposed surveillance system for a hospital that intends to reduce barriers to improve the safety of medical devices. An effective medical device surveillance system should incorporate multiple components that accurately document and assess the appropriate actions to reduce the risk of incidents, adverse events, and patient harm. An AMDE database and medical/equipment library, an open communication and feedback strategy, as well as an education and training program would be developed to increase the hospital staff members' awareness 


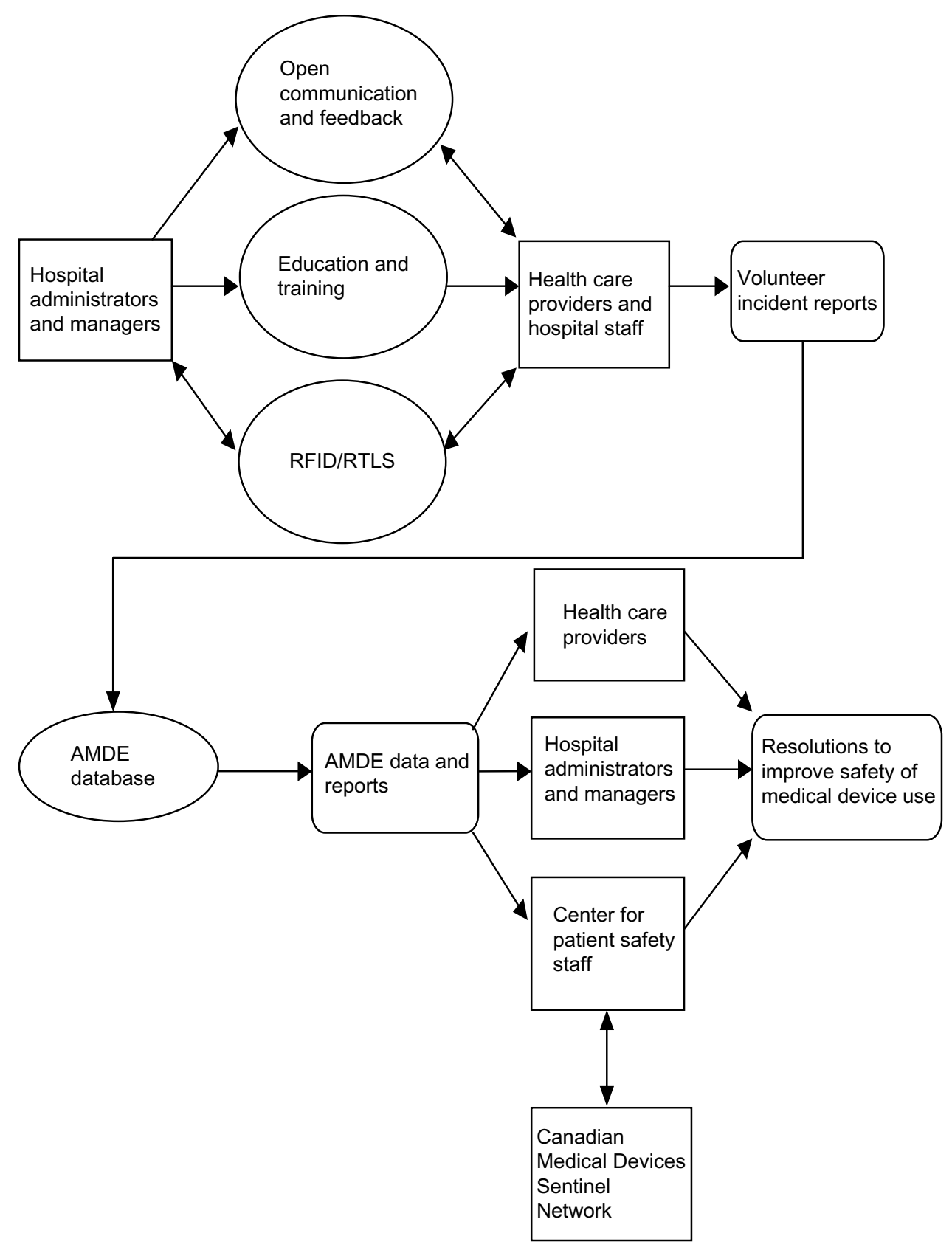

Figure I Proposed medical device surveillance system process in a Canadian hospital.

Abbreviations: AMDE, adverse medical device event; RFID/RTLS, radio frequency identifier/real-time location systems.

and understanding of the purpose and objectives of the surveillance system. ${ }^{19}$

\section{AMDE database}

The AMDE database would detect signals of previously unidentified AMDEs or near misses and identify any trends on AMDEs. ${ }^{19}$ The data from the volunteer incident reports submitted by the health care providers would enable the hospital staff to

- detect rare or unexpected AMDEs;
- detect problems that occur in clinical practice;

- access complete information on AMDEs, including the specific nature of the device, brand, and model number;

- appreciate the public health burden imposed by AMDEs of specific types or related to specific device types; and

- identify appropriate resolutions to minimize risk of AMDEs or near misses for specific devices.

The data collected in the AMDE database should accurately represent the incident and allow the health care providers to describe the error from their perspective. ${ }^{19}$ 


\section{Education and training}

The complexity of decisions, systems, processes, standards, devices, and human interactions with machines are all contributing to the confusion as to what constitutes an AMDE. ${ }^{17}$ In addition, the specific device used on a patient is usually omitted from the patient record. Instructions for device use tend to be written in medical jargon for health care providers and are difficult for lay users or patients to understand and follow. ${ }^{19}$ Human error also is thought to be a major cause of medical device failure that often results in patient injury. Educating health care professionals about the surveillance system, purpose, and benefits to the health care community would help to decrease the risk of underreporting medical device errors. ${ }^{19}$ For instance, data collected in the surveillance system could be used to identify potential limitations related to the institution's resources, lack of staff, or additional training required. Furthermore, training health care professionals on how to recognize adverse events, incidents, or malfunctions associated with the use of medical devices, what to report, how to report, and why to report would encourage them to report errors more frequently (Polisena et al, unpublished data, 2014). ${ }^{20}$

\section{Open communication and feedback strategy}

A systematic review on factors that influence incident recognition, reporting, and resolution found that communication and feedback had an impact on error reporting by health care professionals (Polisena et al, unpublished data, 2014). Based on responses from physicians and nurses in three public hospitals in Turkey, 38\% (6 standard deviation [SD]) felt that the feedback on and communication about medical errors was open, as well as feedback provided to staff about any changes based on event reports (30\%; 4 SD). Only 15\% (4 SD) of errors, however, were reported. ${ }^{23}$ Forty-seven percent (9 SD) of hospital staff indicated that they are informed of errors that occur in their hospital units, and 42\% (6 SD) are approached to discuss strategies to prevent future errors. ${ }^{23}$ In another survey, over 50\% of doctors and nurses indicated they did not receive feedback on their reported errors and were unaware they resulted in any changes. ${ }^{24}$ Furthermore, telephone interviews conducted by Polisena et al (Polisena et al, unpublished data, 2014) also revealed some frustration among frontline clinicians with the lack of feedback from their institution when they reported a medical device-related incident.

Benn et $a{ }^{25}$ proposed a safety feedback loop for safety incidents at the organizational level. The cycle consists of the following major steps: 1) receipt, screening, and archiving of incoming reports; 2) analysis of trends in aggregated incident data and investigation in root causality for incidents is essential to focus corrective efforts on repeating issues; and 3) development and implementation of system improvements to prevent recurrence and address system vulnerabilities. ${ }^{25}$ Examples of outcomes collected from the safety-feedback loop include alerts about new hazards based on incident reports, trends, and best practices identified from surveillance systems..$^{25}$ Individual adverse events or incidents can be monitored closely to determine an appropriate resolution and potential weakness in the safety surveillance system.

Follow-up with health care professionals on the outcome of their reported error would help to increase the frequency of errors reported (Polisena et al, unpublished data, 2014). ${ }^{20}$ Some examples of successful feedback mechanisms previously employed involve safety committee processes, publications, electronic dissemination, staff bulletins, manuals, and conferences. In one study, newsletter distribution and information dissemination at monthly departmental meetings resulted in increased incident reporting rates. ${ }^{25}$ Mahajan acknowledged that additional evidence is required to understand the impact of these techniques on the safety of medical devices and patient care in general. ${ }^{21}$

\section{Integration of medical devices with information systems}

The installation and maintenance of radio frequency identifier/ real-time location systems are important to identify, track, and manage the location of equipment, monitor temperature and sterilization, track consumables and manage inventory, and track staff and patients in health care institutions. ${ }^{26}$ In addition, medical device connectivity is a technology that links medical devices with information systems to reduce the risk of human error in entering clinical data. ${ }^{27}$

\section{Canadian Medical Devices Sentinel Network}

The Canadian Medical Devices Sentinel Network (CMDSNet) involves a group of dedicated and trained representatives from at least ten acute or community-based health care facilities within Canada. These representatives report adverse events associated with the use of medical devices to the Marketed Pharmaceutical and Medical Devices Bureau of Health Canada. The reports sent help regulators to better characterize how hospital facilities use devices, how problems are perceived and reported, and which aspects of the system contribute to a particular event, potentially mitigating risk at an earlier stage. Hospitals benefit from timely new safety information to make informed decisions concerning the 
appropriate use of medical devices due to more comprehensive incident data and earlier regulatory interventions. ${ }^{28}$

As a participating member of the CMDSNet, a hospital would benefit from the following outcomes: ${ }^{28}$

- Increased awareness by hospital frontline users about the benefits of reporting incidents and knowledge of safe medical device usage

- Establishment of a direct communication link between the hospital and Health Canada

- Access to early warnings and signal detection

- Development of a sense of community among CMDSNet users, through an information sharing forum

- Creation of a feedback loop within the network In addition to signing a confidentiality agreement with Health Canada, the involvement of participating hospital facilities is as follows:

- Establish internal processes to increase awareness of error reports via CMDSNet

- Identify two to four main reporters in the hospital as official representatives to CMDSNet

- Respond to questions from Health Canada about submitted reports

- Respond to "ad hoc" adverse event questions

- Receive and disseminate information from the monthly CMDSNet Bulletin

- Participate in a monthly teleconference with members of CMDSNet

Although CMDSNet is exclusive to Canada, similar networks or initiatives in other jurisdictions to monitor incidents, adverse events, or malfunctions associated with the use of medical devices in a hospital context would also be applicable to the proposed framework. For instance, the Medical Product Safety Network in the United States is a device surveillance network of approximately 280 hospitals that was established to monitor device use and adverse events associated with their use. ${ }^{29}$

\section{Important considerations for medical device surveillance systems Cost items of proposed medical device surveillance system}

Individual cost items associated with the proposed medical device surveillance system framework are not readily available. Table 1 highlights the main direct cost items associated with the development, operations, and upgrades and enhancements with the proposed medical device surveillance system. Direct costs are costs that are directly linked to the production and services of the surveillance system, and they can be further divided into fixed and variable costs. Examples of fixed costs include equipment and software purchases, while variable costs vary with the volume of activity. ${ }^{30}$ Development costs involve mostly fixed costs, such as equipment and software purchases. Personnel, operating, and maintenance costs are associated with daily system maintenance and are comprised primarily of variable costs. Upgrade and enhancement costs are related to any system improvements and upgrades. ${ }^{30}$

\section{Potential benefits of proposed medical device surveillance system}

The potential benefits of the proposed medical device surveillance system from patient, health care professional,

Table I Cost items of proposed medical device surveillance system framework

\begin{tabular}{|c|c|c|}
\hline Phase & Cost category & Individual cost items \\
\hline Developmental & $\begin{array}{l}\text { Equipment } \\
\text { Human Resources } \\
\text { Education and training } \\
\text { Overhead }\end{array}$ & $\begin{array}{l}\text { - Equipment purchases (eg, servers, computer software, and licenses) } \\
\text { - Miscellaneous computer equipment (eg, computers, laptops, personal computer wireless cards) } \\
\text { - Hourly costs of hospital staff members involved, including staff in Center for Patient Safety, } \\
\text { biomedical engineers, and information technology staff } \\
\text { - Preparation of user and training manuals and presentations for hospital staff members } \\
\text { - Training of two or three reporters among hospital staff to represent hospital at CMDSNet } \\
\text { - Public utilities (eg, telephone service and Internet connectivity) }\end{array}$ \\
\hline Operating and maintenance & $\begin{array}{l}\text { Equipment } \\
\text { Human resources } \\
\text { Education and training } \\
\text { Overhead }\end{array}$ & $\begin{array}{l}\text { - Maintenance of surveillance system } \\
\text { - Depreciation of equipment and eventual replacement costs } \\
\text { - Personnel costs related to performance of quality control and data review and receiving } \\
\text { feedback from intended users } \\
\text { - Data report production } \\
\text { - Continued education and training of new and current staff members } \\
\text { - Public utilities (eg, telephone service and Internet connectivity) }\end{array}$ \\
\hline Upgrades and enhancements & $\begin{array}{l}\text { Equipment } \\
\text { Human resources } \\
\text { Education and training } \\
\text { Overhead }\end{array}$ & $\begin{array}{l}\text { - System upgrades and enhancements based on feedback from intended users } \\
\text { (eg, increase flexibility in data entry, and render user interface more intuitive) } \\
\text { - Provide education and training of system upgrades and enhancements to intended users } \\
\text { - Public utilities (eg, telephone service as Internet connectivity) }\end{array}$ \\
\hline
\end{tabular}

Abbreviation: CMDSNet, Canadian Medical Devices Sentinel Network. 
and institutional perspectives are highlighted in Table 2. The post-market medical device surveillance will be strengthened with the proposed system. Also, the surveillance data can lead to the development of a conceptual framework of factors that influence device incident occurrence, recognition, reporting, and resolution, thus leading to enhanced patient safety and improved clinical outcomes. In summary, the proposed surveillance system would facilitate the monitoring of device-related incidents and reduce the risk of adverse events or device malfunctions, leading to improved patient care and decreased risk of health professional and institutional liabilities.

\section{Implementation of proposed medical device surveillance system}

The surveillance system should be pilot tested for a predetermined time frame to a select group of hospital decisionmakers and health care professionals prior to its release on a broader scale. These individuals would represent the demographics of intended users. Items to be tested include data to be collected by the surveillance system, such as the data sources and collection methods, and procedures on data handling. The pilot test will not only collect feedback about the value of data collected and ease of use, but identify and correct any possible weaknesses in the system. To ensure a smooth transition in the hospital, the implementation phase would be divided into numerous sub-phases, where the surveillance system would be installed in one hospital ward at a time (eg, cardiac care and cancer care) to further identify and resolve any potential glitches in the system. Information technology staff would be on-call throughout the implementation phase to resolve any potential errors or answer questions from the intended users in order to ensure a seamless surveillance system launch.

\section{Critical incident analysis}

During the critical incident analysis phase, assigned hospital staff members from clinical, biomedical engineering, infection control, and other relevant departments must understand what happened, how and why the incidents occurred, and identify appropriate actions to resolve each situation. Following the implementation of these actions, their impact must be monitored, evaluated, and shared with all parties involved..$^{31}$ Vincent et $\mathrm{al}^{32}$ proposed a critical incident analysis framework based on evidence in the published literature. The framework provides investigators with a structured approach on how to perform a comprehensive critical incident analysis by outlining the main factors and related contributory factors for consideration. It is important to note that errors that do not result in patient adverse events (ie, near misses) are not excluded from the analysis process. ${ }^{32}$

\section{Evaluation of proposed medical device surveillance system}

Surveillance systems are dynamic and require acceptance from intended users to render them successful. Moreover, they

Table 2 Potential benefits of proposed medical device surveillance system

\begin{tabular}{|c|c|}
\hline Perspective & Individual potential benefits \\
\hline Patient & $\begin{array}{l}\text { - Reduced risk of adverse event, incident, or malfunction and failure associated with the use of medical devices } \\
\text { - Fewer patient complications and decreased length of hospital stay as a result of AMDEs or device malfunctions and failures } \\
\text { - Reduced patient morbidity and mortality } \\
\text { - Surveillance data will be instrumental in the identification of patterns associated AMDEs or medical devices prone to } \\
\text { malfunctions or incidents }\end{array}$ \\
\hline $\begin{array}{l}\text { Health care } \\
\text { professional }\end{array}$ & $\begin{array}{l}\text { - Increased awareness of error reporting system and transparency among hospital staff members } \\
\text { - Decreased risk of health professional liability } \\
\text { - Surveillance data would be used to identify and define training needs among hospital staff members }\end{array}$ \\
\hline Institutional & $\begin{array}{l}\text { - Decreased risk of institutional liability } \\
\text { - Early signal detection of the AMDEs or device malfunctions would lead to a quicker response by the health care provider } \\
\text { and hospital } \\
\text { - Participation in and information sharing with members of CMDSNet } \\
\text { - Regular communication with Health Canada to improve product labeling, user manual, and product by manufacturers } \\
\text { - Reports produced from surveillance data will be disseminated to hospital administrators and managers, as well as health } \\
\text { care professionals } \\
\text { - Increased transparency among patients, health care professionals, and hospital decision-makers } \\
\text { - More accurate forecasting of expenditures and minimized ad hoc expenditures } \\
\text { - Cost savings related to standardization, lower maintenance cost, reduced search time for equipment, less delay in patient } \\
\text { treatment and equipment downtime }\end{array}$ \\
\hline
\end{tabular}

Abbreviations: AMDE, adverse medical device event; CMDSNet, Canadian Medical Devices Sentinel Network. 
must be flexible enough to incorporate changes to ensure their relevance over time. It is important to understand how hospital decision-makers and health care providers plan to use the surveillance data. Data quality, timeliness, credibility, leadership, and persistence in data feedback processes were identified as additional important factors to surveillance systems that will improve patient safety. ${ }^{25}$

Once the surveillance system has been in operation for a predetermined time frame, a comprehensive evaluation should be conducted to measure its utility in and impact on the reduction of barriers to reporting AMDEs, incidents, and device malfunctions by health care professionals. Health care providers and hospital administrators would be asked to complete anonymized surveys, as well as participate in individual interviews or focus groups to solicit feedback on the communication strategies, education and training program, and overall user experience with the surveillance system. The evaluation would determine whether the surveillance system met its objectives. Questions might be, for example, Was the data collected in the system relevant and timely? Was it useful for hospital administrators and health care providers? Was the system easy to use? Would the hospital administrators and health care providers continue to use the system? Are there opportunities to further enhance the attributes of the system? The surveillance system also would be evaluated to measure its impact on reducing the risk of patient complications, length of hospital stay, plus morbidity and mortality based on the surveillance data and patient records. Periodic evaluations, both from functional and technical perspectives, are necessary to determine effective actions to maintain the relevance of the surveillance system. ${ }^{33}$ For example, if surveillance data revealed that defibrillators failed to deploy repeatedly due to human factors, then a training program on the appropriate use of the device would help to reduce this type of incident in a measurable way. Conversely, if the root cause of the same issue was uncharged batteries, then a program that ensures that defibrillators stay plugged-in could reduce this type of incident and be beneficial.

\section{Conclusion}

We propose a framework to improve the safety of medical devices used in a Canadian hospital facility based on evidence in the literature and interview responses on factors that influence the recognition, reporting, and resolution of device-related incidents. Our assessment suggests that a medical device surveillance program that combines an AMDE database, education and training program, medical device and equipment library, and open communication and feedback strategy would be instrumental to improve patient care. We advise that direct costs of the surveillance system be calculated both in the planning and implementation phases of the initiatives, while the benefits would be assessed in the implementation phase in order to evaluate the impact of the safety of medical devices in the hospital. A partial or complete implementation of the proposed framework in a Canadian hospital facility would facilitate an assessment of its effectiveness in patient safety enhancement.

\section{Acknowledgments}

This work has been completed in partial fulfillment of the requirements for Julie Polisena's $\mathrm{PhD}$ degree in Epidemiology at the University of Ottawa. Julie Polisena is funded by the Ontario Graduate Scholarship.

\section{Disclosure}

The authors report no conflicts of interest in this work.

\section{References}

1. Maisel WH. Medical device regulation: an introduction for the practicing physician. Ann Intern Med. 2004;140(4):296-302.

2. O'Keeffe $\mathrm{K}$. The rise of medtech [webpage on the Internet]. June 10, 2011 [cited January 2, 2012]. Available from: http://www.mddionline. com/article/rise-medtech. Accessed April 7, 2014.

3. Vincent C, Neale G, Woloshynowych M. Adverse events in British hospitals: preliminary retrospective record review. BMJ. 2001;322(7285): 517-519.

4. Lowery A, Strojny J, Puleo J; Division of Small Manufacturers Assistance, Office of Health and Industry Programs. Medical Device Quality Systems Manual: A Small Entity Compliance Guide. 1st ed. HHS Publication FDA 97-4179. Rockville, MD: Center for Devices and Radiological Health (CDRH), Food and Drug Administration, US Department of Health and Human Services; 1996. Available from: http:// www.gmp-compliance.org/guidemgr/files/MDQS.MANUAL.PDF. Accessed November 11, 2013.

5. Quality systems ISO 13485 [webpage on the Internet]. Ottawa: Health Canada; 2013. Available from: http://www.hc-sc.gc.ca/dhp-mps/md-im/ qualsys/index-eng.php. Accessed February 26, 2014.

6. fda.gov [homepage on the Internet]. National medical device postmarket surveillance plan. Silver Spring, MD: US Department of Health and Human Services, Food and Drug Administration; 2014. Available from: http://www.fda.gov/aboutfda/centersoffices/officeofmedicalproductsandt obacco/cdrh/cdrhreports/ucm301912.htm. Accessed February 26, 2014.

7. US Food and Drug Administration. Strengthening Our National System for Medical Device Postmarket Surveillance. Update and Next Steps. Silver Spring, MD: US Food and Drug Administration; 2013. Available from: http://www.fda.gov/downloads/MedicalDevices/Safety/ CDRHPostmarketSurveillance/UCM348845.pdf. Accessed February 26, 2014.

8. Advisories, Warnings and Recalls - Drugs and Health Products [webpage on the Internet]. Ontario: Health Canada; 2013. Available from: http:// www.hc-sc.gc.ca/dhp-mps/advisories-avis/index-eng.php\#share. Accessed April 24, 2014

9. Office of the Auditor General of Canada [homepage on the Internet]. Chapter 6 - Regulating medical devices - Health Canada. In: Jun 2011 status report of the Auditor General of Canada. Ottawa: Office of the Auditor General of Canada; 2011. Available from: http://www.oag-bvg.gc.ca/internet/English/ parl_oag_201106_06_e_35374.html. Accessed March 15, 2013. 
10. Neumann PJ, Tunis SR. Medicare and medical technology - the growing demand for relevant outcomes. N Engl J Med. 2010;362(5):377-379.

11. Curfman GD, Morrissey S, Drazen JM. The Medical Device Safety Act of 2009. N Engl J Med. 2009;360(15):1550-1551.

12. Ross $\mathrm{S}$, Robert M, Harvey MA, et al. Ethical issues associated with the introduction of new surgical devices, or just because we can, doesn't mean we should. J Obstet Gynaecol Can. 2008;30(6):508-513.

13. Battles JB, Stevens DP. Adverse event reporting systems and safer healthcare. Qual Saf Health Care. 2009;18(1):2.

14. Torrence ME. Data sources: use in the epidemiologic study of medical devices. Epidemiology. 2002;13 Suppl 3:S10-S14.

15. Dhruva SS, Bero LA, Redberg RF. Strength of study evidence examined by the FDA in premarket approval of cardiovascular devices. JAMA. 2009;302(24):2679-2685.

16. Mehran R, Leon MB, Feigal DA, et al. Post-market approval surveillance: a call for a more integrated and comprehensive approach. Circulation. 2004;109(25):3073-3077.

17. David Y, Hyman W, Woodruff VD, Howell M. Overcoming barriers to success: collecting medical device incident data. Biomed Instrum Technol. 2007;41(6):471, 473-475.

18. Cohen MR. Why error reporting systems should be voluntary. BMJ. 2000;320(7237):728-729.

19. Brown LS, Bright RA, Tavris DR, editors. Medical Device Epidemiology and Surveillance. Chicester, UK: John Wiley \& Sons, Ltd; 2007.

20. Hartnell N, MacKinnon N, Sketris I, Fleming M. Identifying, understanding and overcoming barriers to medication error reporting in hospitals: a focus group study. BMJ Qual Saf. 2012;21(5):361-368.

21. Mahajan RP. Critical incident reporting and learning. Br J Anaesth. 2010;105(1):69-75.

22. Samore MH, Evans RS, Lassen A, et al. Surveillance of medical devicerelated hazards and adverse events in hospitalized patients. JAMA. 2004;291(3):325-334.

23. Bodur S, Filiz E. Validity and reliability of Turkish version of "Hospital Survey on Patient Safety Culture" and perception of patient safety in public hospitals in Turkey. BMC Health Serv Res. 2010;10:28.

24. Evans SM, Berry JG, Smith BJ, et al. Attitudes and barriers to incident reporting: a collaborative hospital study. Qual Saf Health Care. 2006;15(1):39-43.
25. Benn J, Koutantji M, Wallace L, et al. Feedback from incident reporting: information and action to improve patient safety. Qual Saf Health Care. 2009;18(1):11-21.

26. Xerafy. Five Myths about RFID and RTLS in the Healthcare Industry. Hong Kong: Xerafy; 2013. Available from: http://www.xerafy.com/ userfiles/misc/resources/whitepapers/Five\%20Myths\%20About $\% 20$ the $\% 20$ Healthcare $\% 20$ Industry $\% 20$ White $\% 20$ Paper.pdf. Accessed November 11, 2013

27. Capsule Tech, Inc. Medical Device Connectivity: Is Waiting Worth the Risk? Andover, MA: CapsuleTech Inc.; 2009. Available from: http:// cdn2.hubspot.net/hub/162893/file-18207151-pdf/docs/medical-deviceconnectivity-is-waiting-worth-the-risk.pdf. Accessed November 11, 2013.

28. Health Canada [homepage on the Internet]. Canadian Medical Devices Sentinel Network pilot project. Ottawa: Health Canada; 2010. Available from: http://www.hc-sc.gc.ca/dhp-mps/medeff/cmdsnet-resscmm-eng. php. Accessed March 16, 2013.

29. fda.gov [homepage on the Internet]. MedSun: medical product safety network. Silver Spring, MD: US Department of Health and Human Services, Food and Drug Administration; January 28, 2014. Available from: http://www.fda.gov/medicaldevices/safety/medsunmedicalprod uctsafetynetwork/default.htm. Accessed February 26, 2014.

30. Kirkwood A, Guenther E, Fleischauer AT, Gunn J, Hutwagner L, Barry MA. Direct cost associated with the development and implementation of a local syndromic surveillance system. J Public Health Manag Pract. 2007;13(2):194-199.

31. Canadian Patient Safety Institute. Canadian Incident Analysis Framework Edmonton: Canadian Patient Safety Institute; 2012. Available from: http://www.patientsafetyinstitute.ca/English/toolsResources/IncidentAnalysis/Documents/Canadian\%20Incident\%20Analysis\%20Framework.PDF. Accessed February 26, 2014.

32. Vincent C, Taylor-Adams S, Stanhope N. Framework for analysing risk and safety in clinical medicine. BMJ. 1998;316(7138):1154-1157.

33. Teutsch SM, Thacker SB. Planning a public health surveillance system. Epidemiol Bull. 1995;16(1):1-6.
Medical Devices: Evidence and Research

\section{Publish your work in this journal}

Medical Devices: Evidence and Research is an international, peerreviewed, open access journal that focuses on the evidence, technology, research, and expert opinion supporting the use and application of medical devices in the diagnosis, treatment and management of clinical conditions and physiological processes. The identification of novel

\section{Dovepress}

devices and optimal use of existing devices which will lead to improved clinical outcomes and more effective patient management and safety is a key feature. The manuscript management system is completely online and includes a quick and fair peer-review system. Visit http://www. dovepress.com/testimonials.php to read real quotes from authors. 